\title{
Low-temperature methane oxidation triggered by peroxide radicals over noble-metal-free $\mathrm{MgO}$ catalyst
}

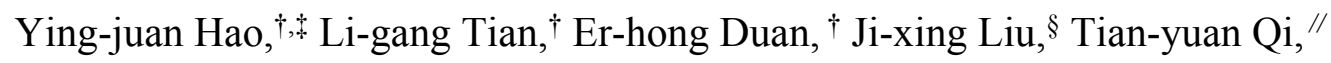

Wei-qi Kong, ${ }^{\dagger}$ Xue-han Qi,${ }^{\dagger}$ Xinying Liu, ${ }^{*},+, \perp$ Ying Liu, ${ }^{\dagger}$ Jun Zhao ${ }^{\dagger}$ and Fa-tang $\mathrm{Li}^{*}, \dot{\dagger}, \dot{+}$

$\uparrow$ College of Science, Hebei University of Science and Technology, Shijiazhuang, 050018, China.

† International Joint Laboratory of New Energy, Hebei University of Science and Technology, Shijiazhuang, 050018, China.

§State Key Laboratory of Heavy Oil Processing, China University of Petroleum, Beijing, 102249, China.

// Institute of Computational Quantum Chemistry, College of Chemistry and Material Science, Hebei Normal University, Shijiazhuang, 050024, China.

$\perp$ Institute for the Development of Energy for African Sustainability (IDEAS), University of South Africa (UNISA), Florida 1710, South Africa.

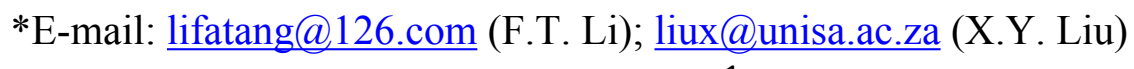




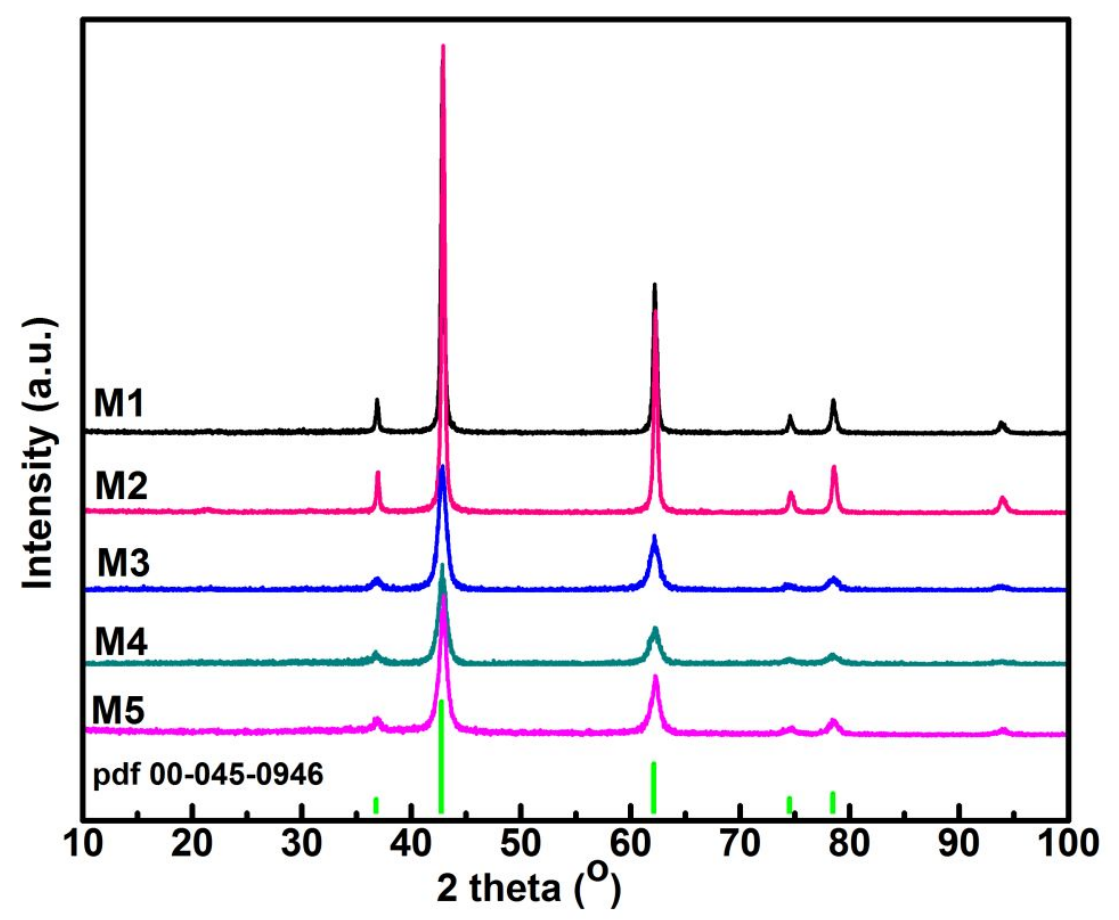

Figure S1. XRD patterns of the as-obtained samples.

Table S1. Synthesis conditions, physical properties, and flat-band potentials of the as-obtained $\mathrm{MgO}$ samples.

\begin{tabular}{|c|c|c|c|c|c|c|}
\hline Samples & $\begin{array}{c}\text { Mg salt/ } \\
\text { urea/ } \\
\text { citric acid } \\
\text { (molar ratio) }\end{array}$ & $\begin{array}{c}\mathrm{S}_{\mathrm{BET} /} \\
\mathrm{m}^{2} / \mathrm{g}\end{array}$ & $\begin{array}{c}\text { Pore } \\
\text { volume } \\
/ \mathrm{cm}^{3} / \mathrm{g}\end{array}$ & $\begin{array}{c}\text { Pore } \\
\text { diameter } \\
/ \mathrm{nm}\end{array}$ & $\begin{array}{c}\text { Crystal } \\
\text { size/nm } \\
\text { (Scherrer } \\
\text { Formula) }\end{array}$ & $\begin{array}{c}\text { Flat-band } \\
\text { potentials vs } \\
\text { RHE/V }\end{array}$ \\
\hline M1 & $1: 1: 0.0$ & 15.8 & 0.104 & 21.8 & 55 & -0.58 \\
\hline M2 & $1: 1: 0.2$ & 14.1 & 0.123 & 27.1 & 34 & -0.63 \\
\hline M3 & $1: 1: 0.4$ & 52.0 & 0.295 & 16.5 & 10 & -0.85 \\
\hline M4 & $1: 1: 0.6$ & 90.7 & 0.369 & 11.2 & 10 & -0.68 \\
\hline M5 & $1: 1: 0.8$ & 69.2 & 0.336 & 12.9 & 10 & -0.68 \\
\hline
\end{tabular}



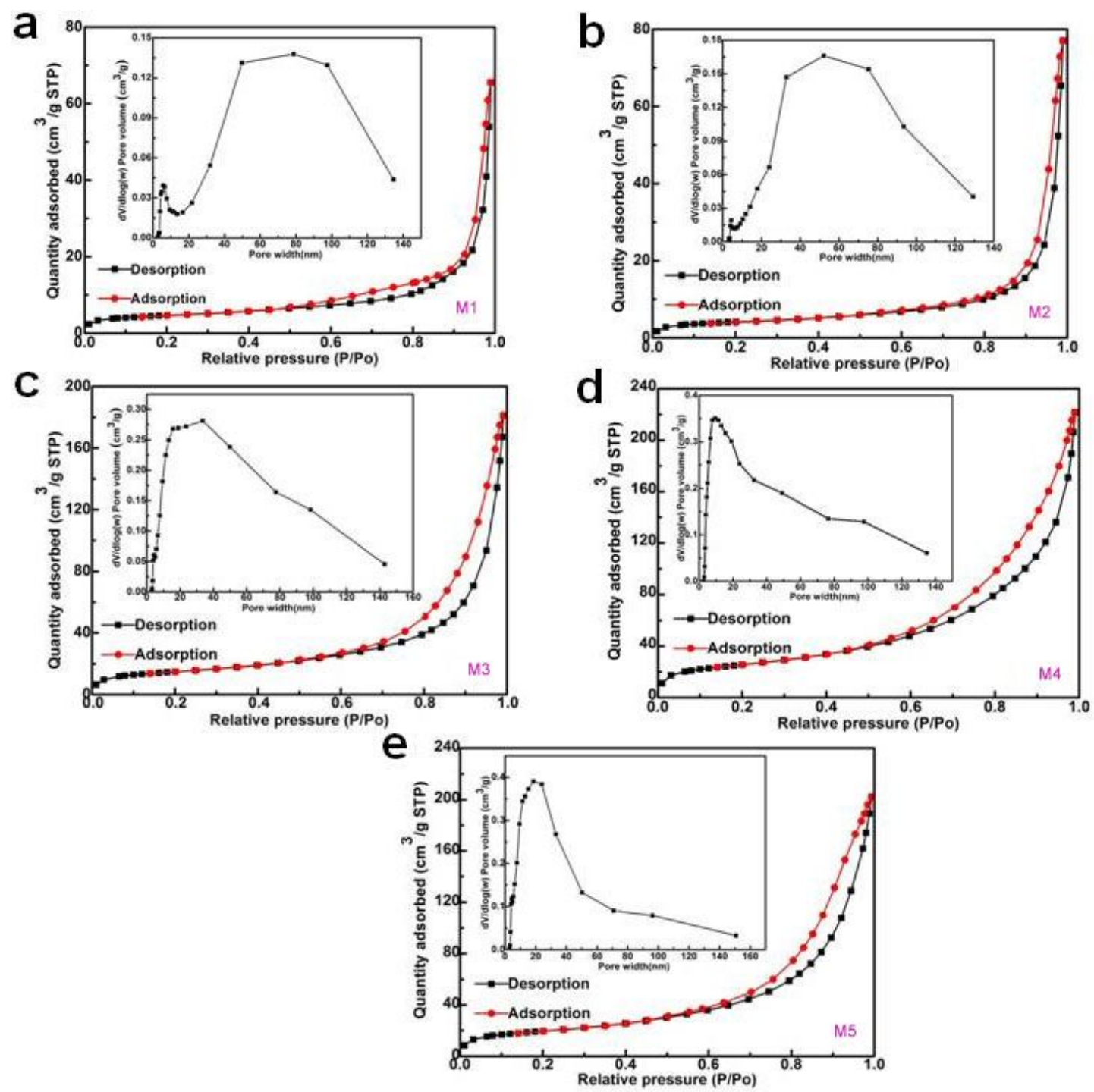

Figure S2. Nitrogen adsorption-desorption isotherms and pore size distributions of M1-M5 samples. 


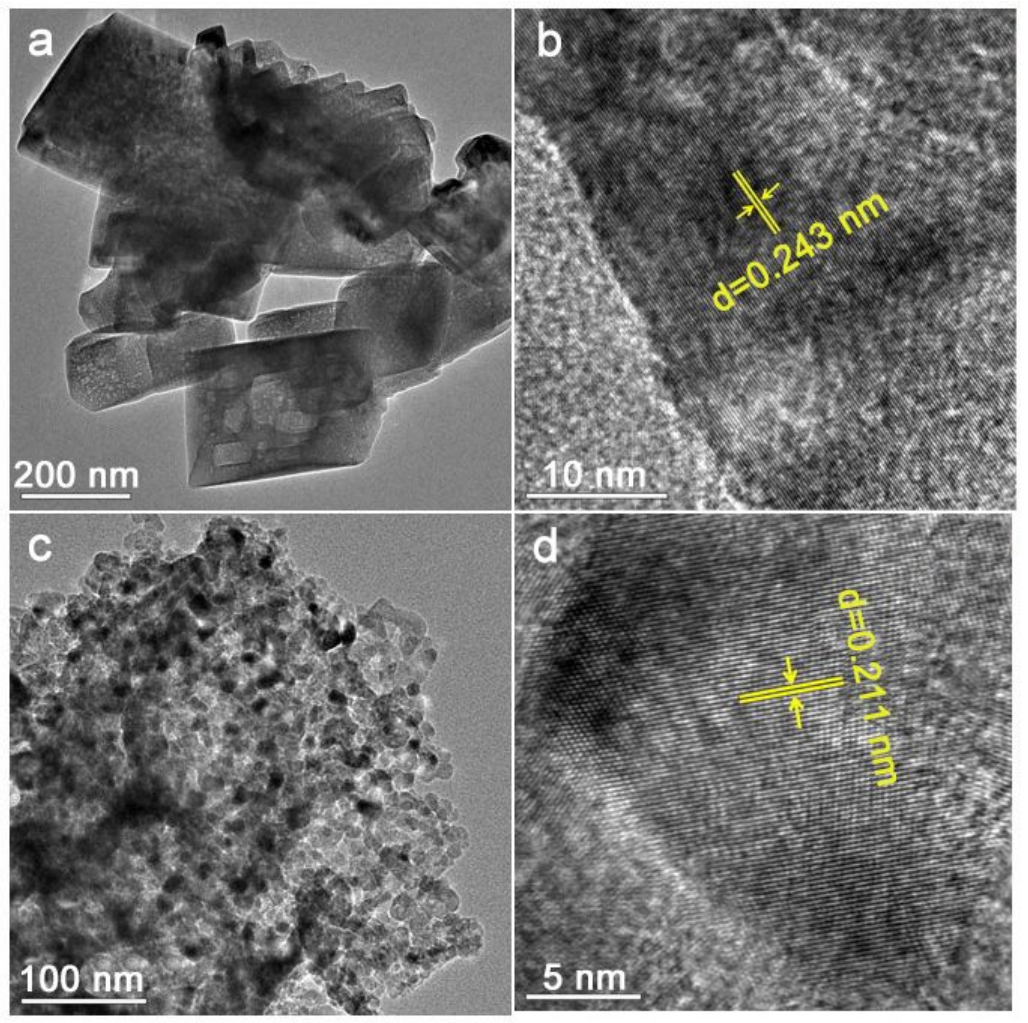

Figure S3. TEM and HRTEM patterns of the M1 ( $a$ and $b$ ) and M3 samples (c and d).

Table S2. Atomic concentrations in M1 sample before and after $\mathrm{Ar}^{+}$etching.

\begin{tabular}{|c|c|c|c|}
\hline \multirow{2}{*}{$\begin{array}{c}\text { Etching times } \\
\text { (s) }\end{array}$} & \multicolumn{3}{|c|}{ Atomic molar concentration (\%) } \\
\cline { 2 - 4 } & $\mathbf{M g}$ & $\mathbf{C}$ & $\mathbf{O}$ \\
\hline 0 & 38.2 & 13.7 & 48.1 \\
\hline 110 & 43.6 & 7.3 & 49.1 \\
\hline 220 & 43.9 & 6.7 & 49.4 \\
\hline
\end{tabular}

Table S3. Atomic concentrations in the M3 sample before and after $\mathrm{Ar}^{+}$etching.

\begin{tabular}{|c|c|c|c|}
\hline \multirow{2}{*}{$\begin{array}{c}\text { Etching times } \\
\text { (s) }\end{array}$} & \multicolumn{3}{|c|}{ Atomic molar concentration (\%) } \\
\cline { 2 - 4 } & $\mathbf{M g}$ & $\mathbf{C}$ & $\mathbf{O}$ \\
\hline 0 & 33.6 & 20.3 & 46.1 \\
\hline 25 & 38.2 & 13.1 & 48.7 \\
\hline 50 & 39.3 & 11.6 & 49.1 \\
\hline
\end{tabular}



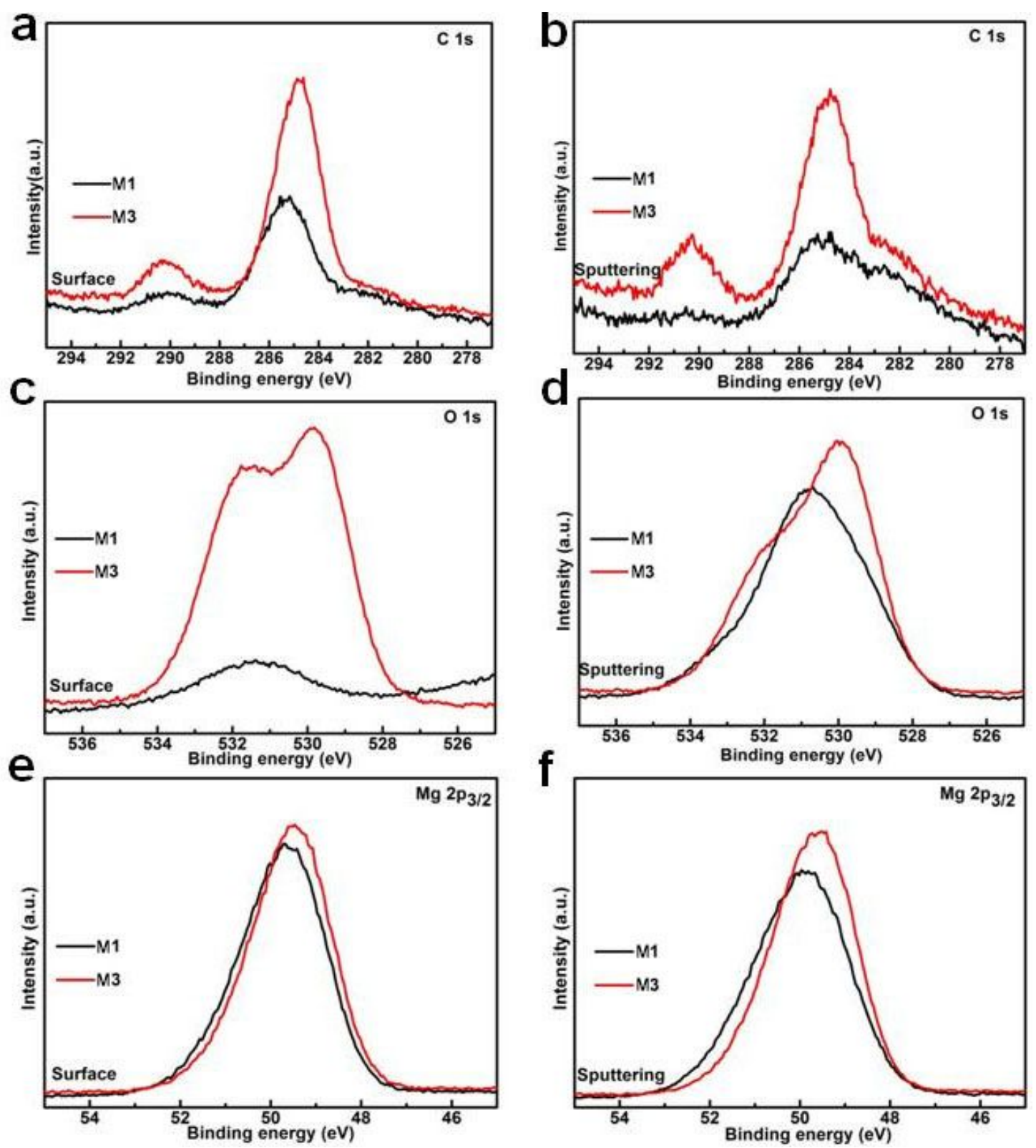

Figure S4. XPS spectra of C1s (a and b), O 1s (c and d) and $\mathrm{Mg} 2 \mathrm{p}_{3 / 2}(\mathrm{e}$ and $\mathrm{f}$ ) in the $\mathrm{M} 1$ and $\mathrm{M} 3$ samples before and after $\mathrm{Ar}^{+}$sputtering. 
a

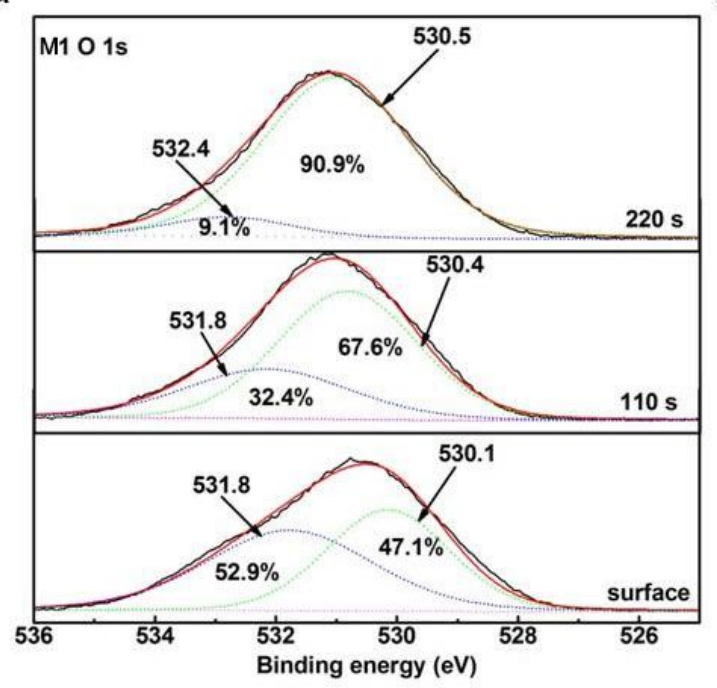

b

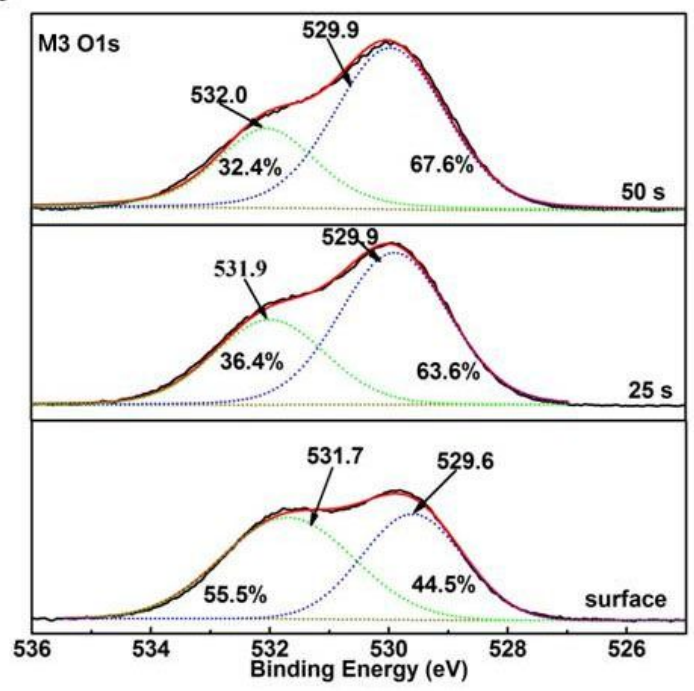

Figure S5. Time-dependent high resolution O1s XPS spectra of the M1 (a) and M3 (b) samples, before and after $\mathrm{Ar}^{+}$etching, respectively.

The time-dependent high resolution XPS spectra of O1s in the M1 and M3 samples, before and after $\mathrm{Ar}^{+}$etching, are displayed in Figure S5. It can be seen that these two typical $\mathrm{O} 1 \mathrm{~s}$ peaks at about 529.8 and $531.9 \mathrm{eV}$ are respectively assigned to $\mathrm{Mg}-\mathrm{O}^{1}$ and oxygen vacancies ${ }^{2}$ or peroxide radical. ${ }^{3}$ 


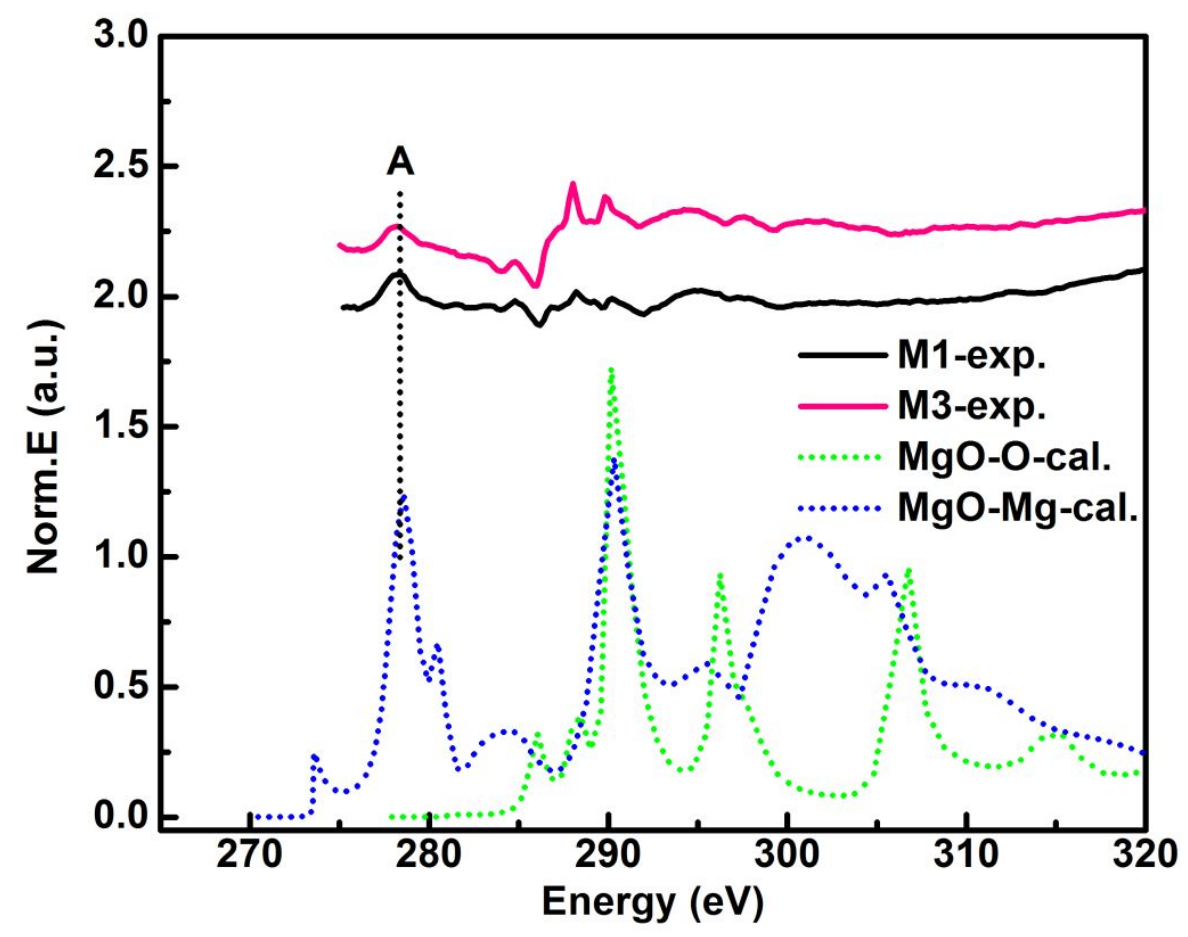

Figure S6. C K-edge XANES spectra for the M1 and M3 samples. 


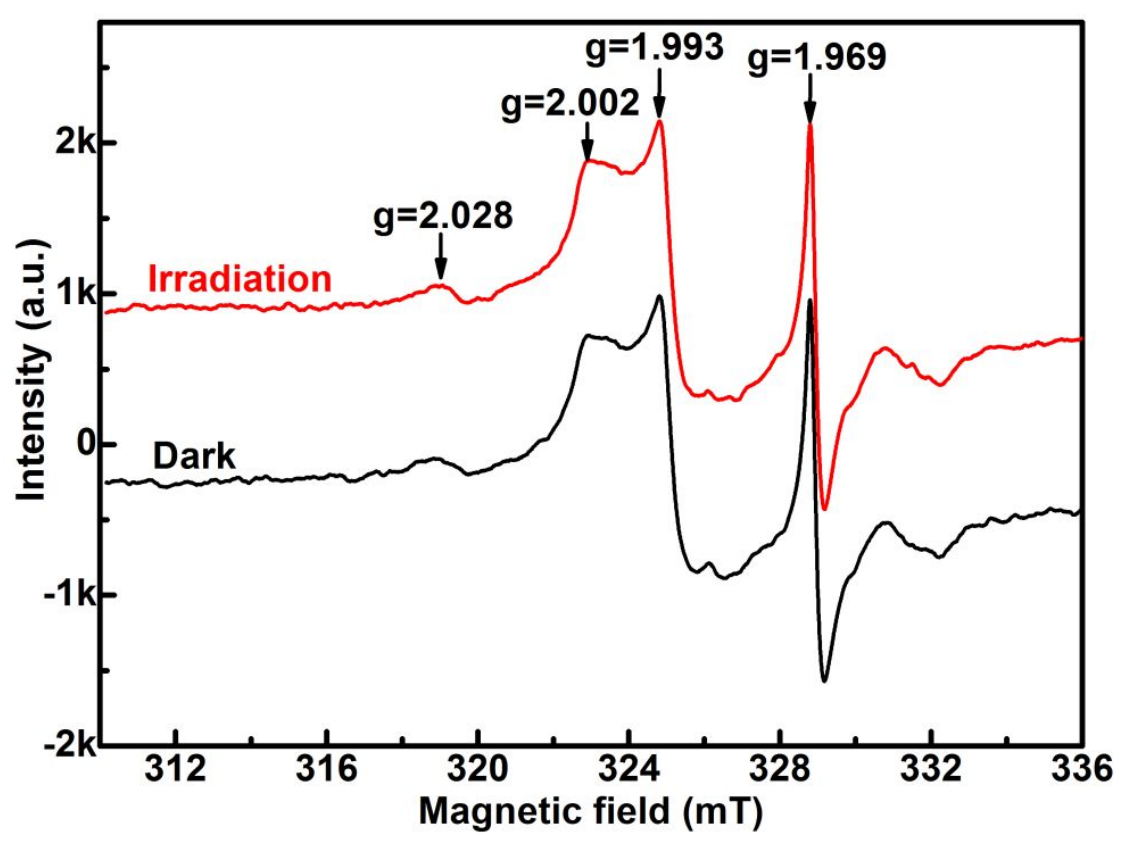

Figure S7. EPR spectra of the M1 sample under different conditions at room temperature.
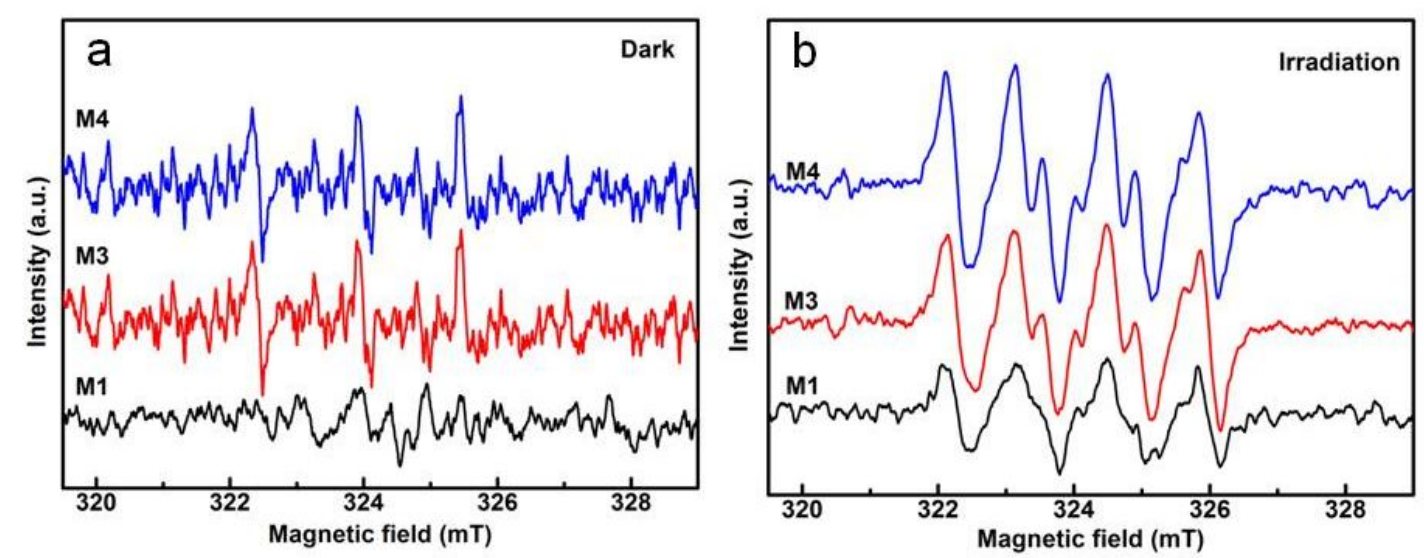

Figure S8. EPR spectra of DMPO- $\cdot \mathrm{O}_{2}{ }^{-}$adducts over the $\mathrm{M} 1, \mathrm{M} 3$ and $\mathrm{M} 4$ samples under different conditions. 


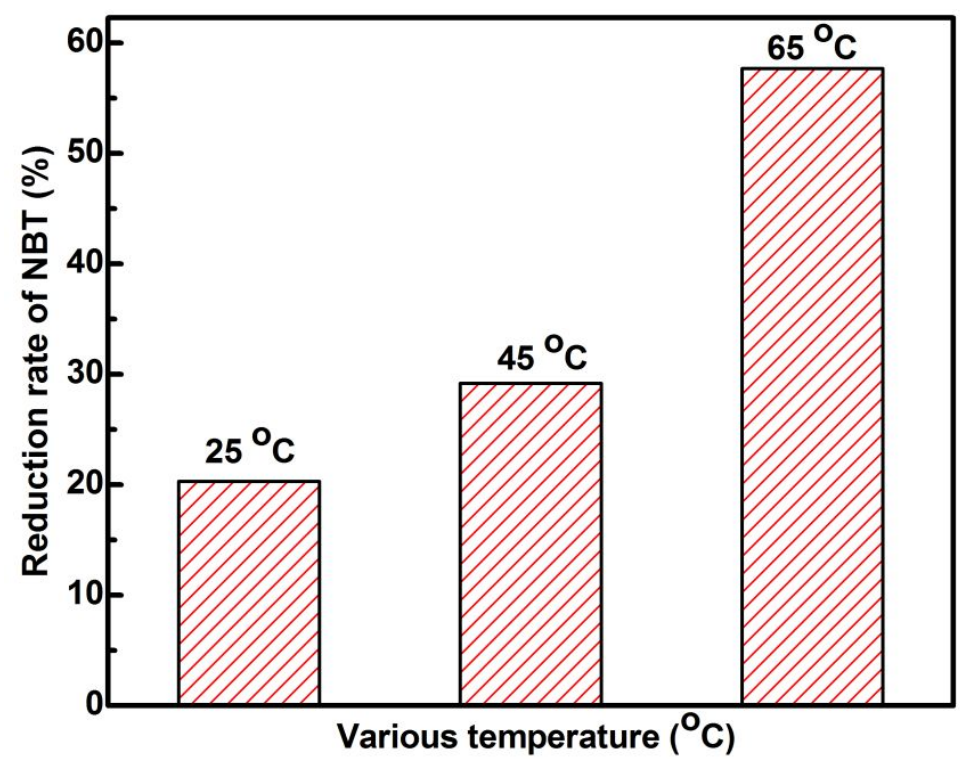

Figure S9. Effect of temperature on reduction rate of NBT by superoxide radicals formed on the M4 sample surface. 


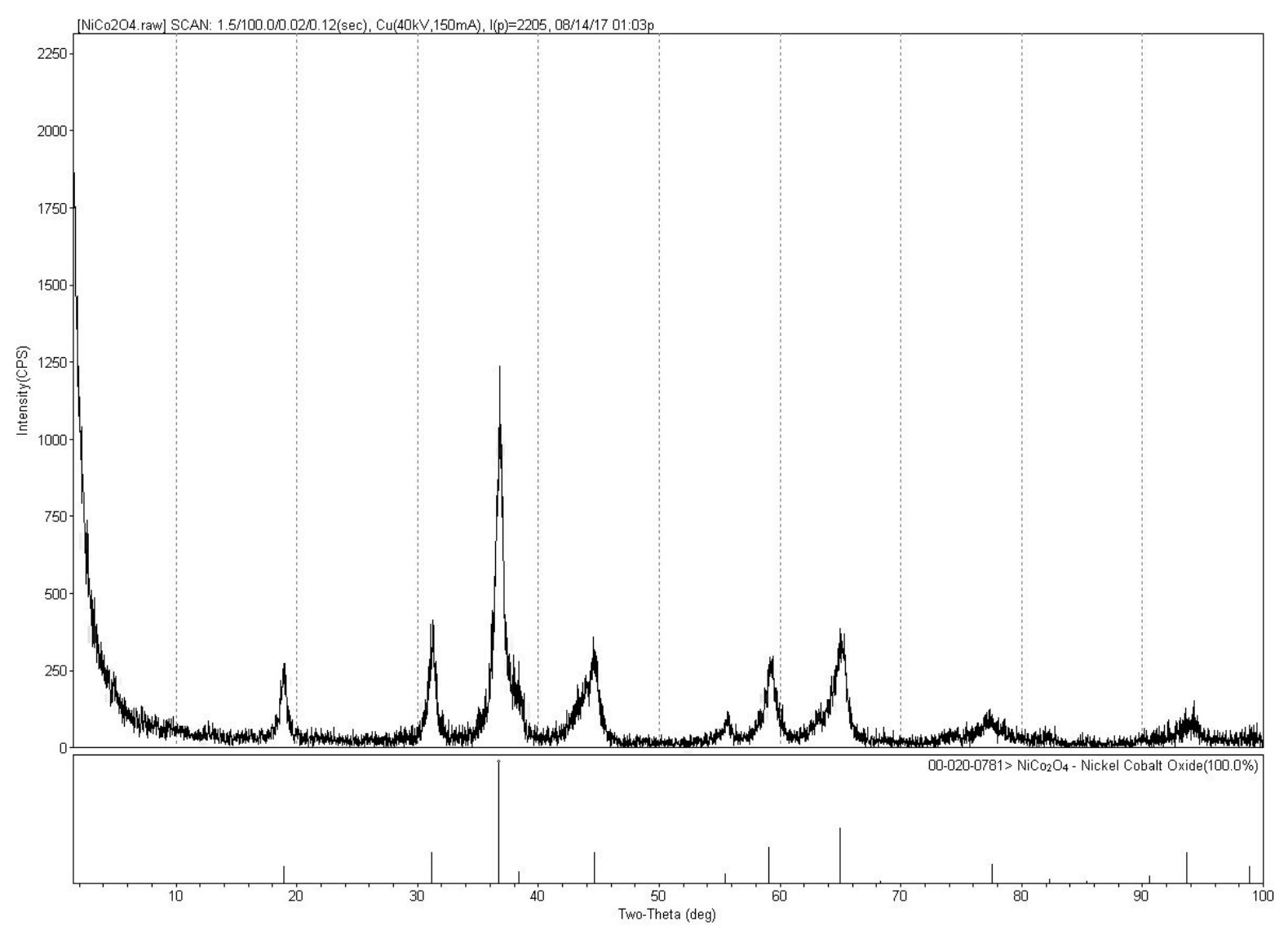

Figure S10. XRD pattern of $\mathrm{NiCo}_{2} \mathrm{O}_{4}$.

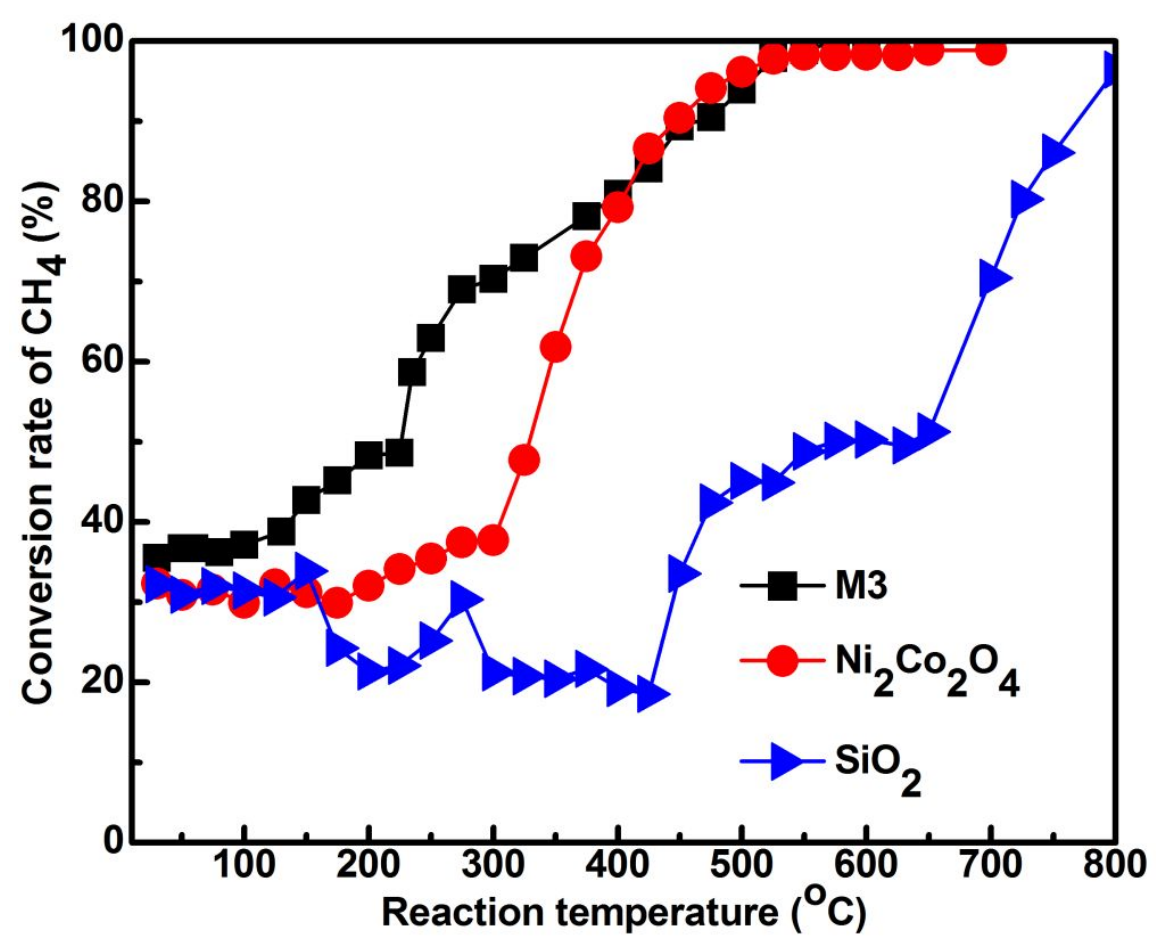

Figure S11. Catalytic performance of methane oxidation over different catalysts without preadsorption treatment: $1 \mathrm{~mL}$ catalyst, $6000 \mathrm{~mL} / \mathrm{h}, 0.2 \mathrm{Mpa}$. 

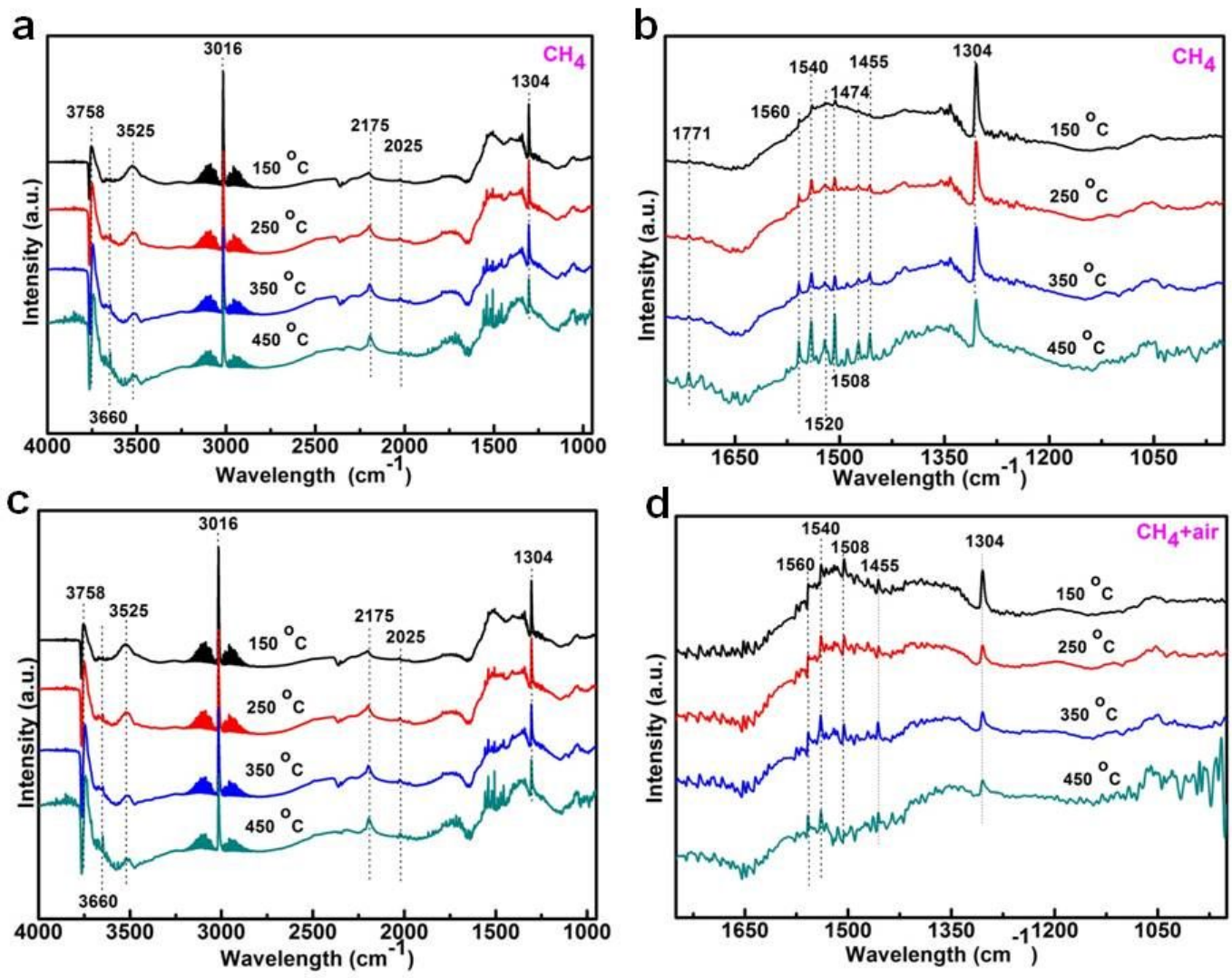

Figure S12. In situ DRIFT spectra of the M3 sample under methane ( $a$ and $b$ ) and a gas mixture of methane/air adsorption (c and d) at various before $\mathrm{N}_{2}$ sweeping temperatures, respectively. 

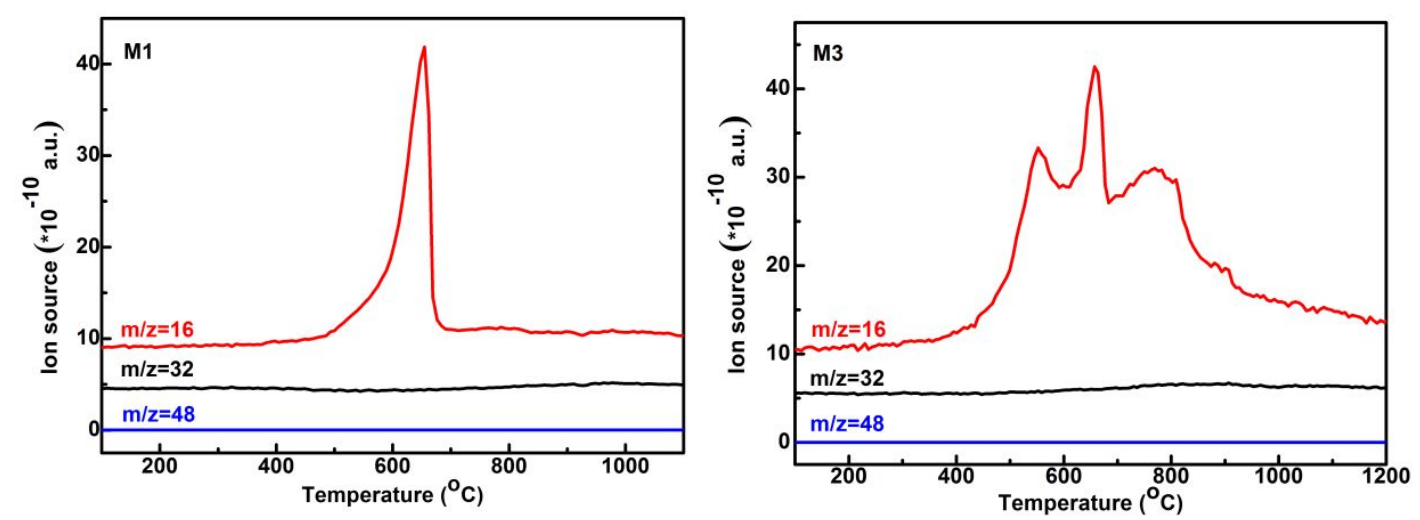

Figure S13. $\mathrm{O}_{2}$-TPD-Mass patterns of the M1 and M3 samples.

\section{References}

(1) Cabailh, G.; Lazzari, R.; Cruguel, H.; Jupille, J.; Savio, L.; Smerieri, M.; Orzelli, A.; Vattuone, L.; Rocca, M. Stoichiometry dependent chemical activity of supported MgO (100) films. J. Phys. Chem. A 2011, 115, 7161-7168.

(2) Müller, K.; Torres, D.; Park, J. B.; Liu, P.; Stacchiola, D.; Starr D. E. $\mathrm{NiO}-\mathrm{MgO}$ and $\mathrm{CoO}-\mathrm{MgO}$ thin-film solid oxide solutions on a Mo (100) support: formation, reduction, and influence of the support. J. Phys. Chem. C 2013, 117, $280-287$.

(3) Jupille, J.; Dolle, P.; Beancon, M. Ionic oxygen species formed in the presence of lithium, potassium and cesium. Surf. Sci. 1992, 260, 271-285. 